\title{
Psychotropic placebos create resistance to the misinformation effect
}

\author{
Seema L. Clifasefi \\ University of Washington, Seattle, Washington \\ Maryanne Garry ANd DAVId N. HARPER \\ Victoria University, Wellington, New Zealand \\ STEFANIE J. SHARMAN \\ University of New South Wales, Sydney, Australia \\ AND \\ RACHEL SUTHERLAND \\ Victoria University, Wellington, New Zealand
}

\begin{abstract}
Can a placebo for a psychotropic drug help participants resist the misinformation effect? To answer this question, we gave participants a mixture of baking soda and water and told half of them that the mixture was a cognition-enhancing drug called R273 and told the other half that it was an inactive version of the drug. Shortly thereafter, all participants took part in a three-stage misinformation experiment. Compared with participants who were told that they had taken the placebo, the participants who were told that they had taken the drug reported improved cognitive abilities and were less susceptible to the misinformation effect. We provide sourcemonitoring and mindfulness accounts of our findings.
\end{abstract}

Placebos can produce powerful effects, including improving people's subjective reports of cognitive performance. However, there is no objective evidence to support these reports: To date, people have shown no placeboinduced improvement in cognitive performance compared with a control group. For example, in the only published positive placebo and memory study, all participants received a placebo, but half were told it was a memoryenhancing drug and the other half were told it was a placebo (Kvavilashvili \& Ellis, 1999). Participants who were told that they had taken the drug (told drug participants) thought that their memories were better than participants who were told they had taken a placebo (told placebo participants); however, both groups performed similarly at recall. Kvavilashvili and Ellis concluded that their findings fit with pharmacological research showing that memory performance is difficult to improve.

It is possible, however, that Kvavilashvili and Ellis's (1999) placebo did not improve memory because the recall task they used was not sensitive to the way in which placebos work. Kirsch and Lynn (1999) suggested that placebos cause people to set in motion a behavioral sequence that produces the effects they think placebos cause. In other words, people cause their own behavior, but they (mis)attribute it to the placebo. Thus, for a placebo to benefit memory, participants must be able to adjust some behavior to improve memory performance but attribute that behavior to the placebo. A recall task does not readily allow participants to make those behavioral adjustments. Therefore, we hypothesized that a memory task that did allow participants who had taken placebos to make behavioral adjustments would show memory benefits. One such task involves the effect of misleading suggestions on memory performance.

In a typical experiment, participants witness an event and then receive either nonmisleading or purposely misleading postevent information (PEI). Later, they are tested on what they can remember about the event. Results reliably show the misinformation effect: Participants more accurately recall items about which they received no misleading information (control items) than items about which they received misleading information (misled items) (Tousignant, Hall, \& Loftus, 1986).

Many social and cognitive factors influence the misinformation effect. Socially, the status of the person delivering the misinformation affects the likelihood that the recipient will adopt the misleading suggestion (see, e.g., Vornik, Sharman, \& Garry, 2003). Cognitively, one's ability to keep track of - and then detect discrepancies between - the event and the misleading narrative also af-

S. L. Clifasefi, seemac@u.washington.edu 
fects one's susceptibility to being misled (Lindsay, 1993). Source monitoring is the process of remembering information and attributing it to the correct source (Johnson, Hashtroudi, \& Lindsay, 1993); as source monitoring improves, people are less likely to be misled.

On the basis of this research, we might expect that if a placebo causes people to set in motion behaviors that result in better source monitoring, they should be better at detecting and discounting the misleading information that causes the misinformation effect. There are at least two ways in which a placebo might affect source monitoring. First, people would be more likely to resist false memories if taking a placebo caused them to shift from their usual automatic source monitoring to slower, more deliberate and effortful source monitoring. When people have a reason to be suspicious of a narrative-if, for example, they are warned it may contain misleading information - they scrutinize it more closely. Consequently, they are more likely to detect the misleading information, which prevents it from corrupting their memories (Tousignant et al., 1986). Moreover, if taking a placebo makes participants believe that they can perform effortful source monitoring more easily, their source monitoring should be more thorough, and they should also believe that various cognitive faculties - such as those related to source monitoring - are enhanced. In sum, if participants take a placebo and consequently set in motion more deliberate and effortful source-monitoring behaviors, they might be better able to resist misleading suggestions.

The second way in which placebos may affect source monitoring is by influencing people's confidence in the accuracy of their source judgments. Johnson et al. (1993) argued that an important part of source monitoring is evaluating the trustworthiness of the information source. If a placebo increases participants' confidence in the accuracy of their memories, then they should trust their memories of the details of an event that they saw, rather than trusting a postevent recounting of it, which should be reflected in higher confidence. These two placebo-induced effects may occur during encoding (while participants are witnessing an event), during presentation of PEI (while participants are detecting discrepancies between it and the event) or during recall (while participants are evaluating the source of the items presented in the event and the PEI).

In conclusion, research suggests that if a placebo can set in motion increased source-monitoring behaviors, then a placebo believed to be a cognition-enhancing drug should be able to reduce the misinformation effect. Indeed, recent research indicates that placebos can cause people to set in motion behaviors that result in poorer source monitoring, which leads to an exaggerated misinformation effect. For example, participants who were told that they were drinking alcohol, but who were really given an alcohol placebo, were more prone to memory distortions than participants who were correctly told that they were drinking a nonalcoholic beverage (Assefi \& Garry, 2003).

In the experiment we present here, our goal was to make participants less susceptible to memory distortions by increasing their source-monitoring activity. We told half of our participants that they were taking R273, a drug that "improves alertness and the ability to detect change." We told the other half that they were taking an inactive, placebo form of R273. In reality, all participants received a placebo.

How should our drug instruction affect the misinformation effect? Let us consider performance on control items. If told drug participants believe that R273 increases attention, they may pay more attention to the event, a behavior that may or may not increase their memory for the event. Understandably, the degree to which participants attend to events or objects affects their memories for those events or objects (Loftus, Loftus, \& Messo, 1987). Thus, we did not predict any particular effect of the placebo for told drug participants' control performance.

Let us now consider performance on misled items. Here, there are at least two reasons to hypothesize that told drug participants may be less misled than told placebo participants. First, told drug participants may scrutinize the PEI more closely while reading it because they believe that their ability to detect change is improved. This enhanced scrutiny and source-monitoring activity may increase their ability to detect discrepancies between the original event and the PEI. Consequently, told drug participants may be better able to reject, at test, the misleading items included in the PEI, resulting in less memory distortion. Second, if told drug participants believe their cognitive faculties are improved, they may be more willing to engage in more difficult, more deliberate, and therefore more effective source-monitoring processes, because they will judge these processes to be less effortful than usual.

Of course, it is entirely possible that a cognition-enhancing drug suggestion may not increase source-monitoring activity. Rather, told drug participants may think that the drug will do the work for them and consequently may expend minimal cognitive effort in observing the event or reading the PEI. Likewise, told placebo participants may be disappointed at not receiving the drug and might show their disappointment by expending minimal effort during the experiment, or they might have the opposite reaction and use more effort during the experiment.

Even if a psychotropic placebo works to protect people from memory distortions, why should we care? Such a finding would be the first demonstration of an objective improvement in memory performance. Furthermore, understanding how we can decrease people's susceptibility to misinformation can help shed light on mechanisms underlying memory distortions.

\section{METHOD}

\section{Participants}

Fifty-six undergraduates participated for course credit. Participants performed the trials in groups of 7 or fewer and did not talk to one another during the experiment.

\section{Materials and Procedure}

The experiment was a 2 (instruction: told drug or told placebo) $\times$ 2 (PEI: control or misleading) mixed design.

Participants signed up for what they thought was a clinical drug trial investigating the effects of a mild stimulant, R273, on visual and verbal learning. In fact, R273 was lime-flavored sodium bicarbonate. An experimenter dressed in a white lab coat posed as a phar- 
maceutical researcher from a drug company and remained present throughout the experiment. The "pharmaceutical researcher" told participants that "extensive research and stringent drug trials over the past 10 years had shown R273 to be safe and effective in aiding mental alertness and cognitive functioning." She also told subjects that research using a close cousin of R273 had given U.S. military radar operators "significant and sustained improvement in their ability to detect changes in their visual field, and to quickly and accurately distinguish enemy target signatures from simple environmental noise." These points were designed to create the expectation in participants that R273 would allow them to more easily perform behaviors associated with source monitoring.

To further cultivate expectations about R273's effects, we falsely warned participants that they might experience a variety of physical sensations, such as tingling fingers (see Epps, Monk, Savage, \& Marlatt, 1998). We "screened" participants for medical conditions and weighed them while they watched a computer calculate the amount of substance (.001 g per $\mathrm{kg}$ of body weight) they were to receive.

Once all of the participants were weighed, a volunteer chose an envelope that ostensibly assigned the entire group to a drug condition. In fact, the envelopes were rigged so that half the participants were assigned to the Active R273 condition and half to the Inactive R273 condition. Then, in plain view of all participants, the pharmaceutical representative measured the powder for each participant from a clearly labeled jar (“Active R273" or "Inactive R273"), dissolved it in a glass of water, and distributed each mixture. Participants drank the concoction and then watched a 10-min action movie clip, which they were told would allow time for the drug to take effect.

After the movie clip, the misinformation experimental phase began. Participants watched slides of a man walking through a bookstore and shoplifting certain items; they then completed a 12-min filler task. Next, they read a narrative containing both generic (i.e., control information that was accurate but incomplete) and misleading information about the slides. There were two versions of the slide sequence and four versions of the narrative, each of which included eight critical items: candle, folder, book, sweatshirt, stapler, magazine, elevator, and towel. Thus, each narrative contained accurate information about four items and misleading information about four items (see the Appendix). Slides and narratives were counterbalanced such that each item appeared equally often as a control and as a misleading item. For example, if participants saw a blue towel in the slides, they might read about either "a towel" (control) or a "white towel" (misleading). After a 3-min filler task, participants took a 20-item, two-alternative forced choice memory test for the slide sequence using pen and paper. They were forced to choose between the item that they actually saw in the slides and the misleading item contained in the narrative. ${ }^{1}$ Participants were instructed to base their answers on what they saw in the slide sequence, not on anything they read afterward.

Participants rated their confidence that their answers were correct on a scale from 1 (not at all confident) to 5 (extremely confident). After the test, participants also rated the following cognitive experiences from 1 (strongly disagree) to 5 (strongly agree): enhanced senses, easier time thinking and remembering, faster response time, better ability to concentrate, and better ability to pay attention during the session.

\section{RESULTS AND DISCUSSION}

Fifty-two subjects completed all phases of the study; ${ }^{2}$ we used an alpha level of .05 for statistical tests. To determine whether our placebo had a positive effect on a subjective measure, we examined participants' cognitive ability ratings. Figure 1 shows that told drug participants thought that their cognitive abilities were better than told placebo participants $[F(1,46)=8.30, p=.01, f=.41]$

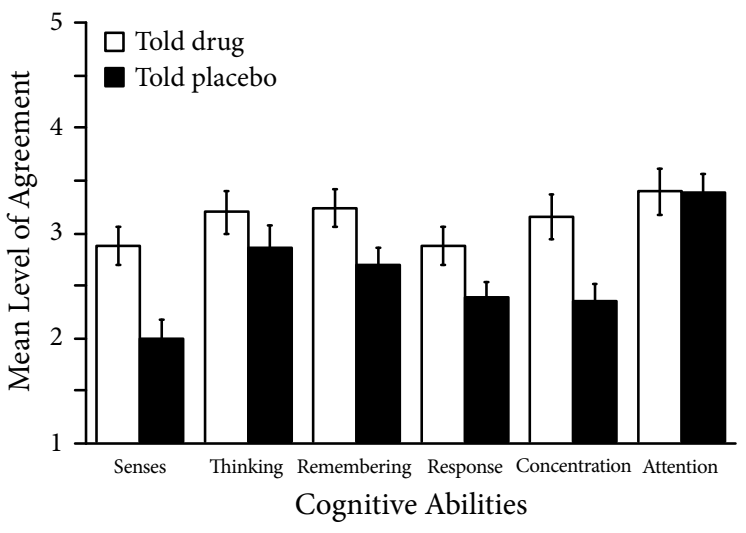

Figure 1. Participants' perceived improvement in cognitive abilities as a function of instruction (told drug or told placebo). Error bars represent standard errors for individual means.

(Cohen, 1988). We now turn to our main research question: Did the placebo have a positive effect on an objective memory measure?

\section{Misinformation Effect}

The "control" side of Figure 2 shows the number of participants' correct responses (out of four) for control items. In other words, this side reflects the number of items participants correctly chose as items they had seen in the slides after they had received generic (i.e., accurate but incomplete) information about those items in the narrative. The "misled" side shows participants' correct responses (out of four) for misled items. That is, this side reflects the number of items participants correctly chose as items they had seen in the slides after they had received misleading information about those items in the narrative.

Figure 2 shows that told drug participants were more resistant to the misinformation effect than told placebo participants, as does the interaction of drug instruction $X$ PEI $[F(1,50)=5.48, p=.02, f=.65]$. Told placebo participants showed the typical misinformation effect,

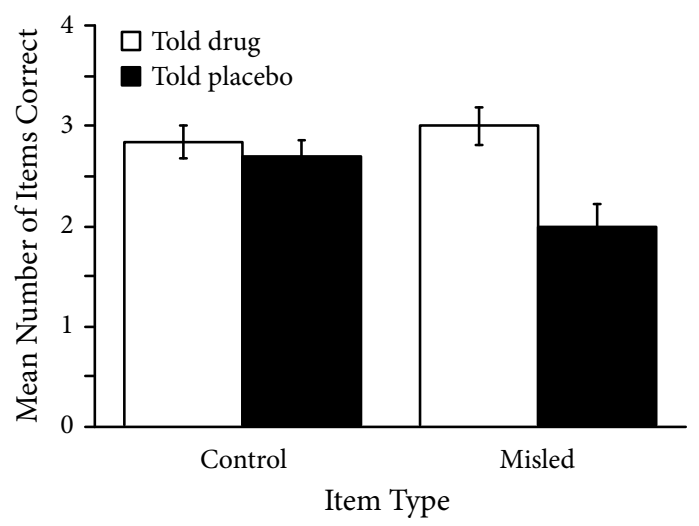

Figure 2. Performance on control and misled items by instruction (told drug or told placebo). Error bars represent standard errors for individual means. 
whereas told drug participants performed as though they had not been exposed to misleading PEI. Moreover, control performance was equal across groups $[t(50)=.68$, $p=.50]$, which indicates that told placebo participants paid attention to the slides and that told drug participants were not letting the drug do the work.

We might expect that told drug participants, who thought their cognitive abilities had improved, would be more confident about their answers on the memory test; we found a marginal main effect for confidence $[F(1,50)=3.14$, $p=.08, f=.25]$. We also investigated participants' confidence for the misled items they incorrectly attributed to the event. Misinformation research typically shows that participants are more confident about their incorrect answers for misled items than their incorrect answers for control items (Assefi \& Garry, 2003). Indeed, we found a similar pattern of results, as shown by the main effect for item type $[F(1,31)=5.06, p=.03, f=.37]$. Told drug participants were also more confident about their incorrect answers than told placebo participants, regardless of whether those answers were for control or misled items, as shown by the main effect for drug instruction $[F(1,31)=$ $5.22, p=.03, f=.41]$. It is important to note that although the told drug group displayed greater confidence than the told placebo group, neither group was overly confident about their answers (told drug, $M_{\text {control }}=2.65, M_{\text {misled }}=$ 3.17 ; told placebo, $M_{\text {control }}=2.20, M_{\text {misled }}=2.76$; on a scale from 1 to 5 ).

\section{Discrimination and Bias}

We predicted that the drug instruction would encourage told drug participants to use more stringent source monitoring criteria than told placebo participants. We used signal detection theory to investigate participants' criteria. We recoded our data as hits (correct responses for control items) and false alarms (incorrect responses for misled items) to calculate discrimination $\left(A^{\prime}\right)$ and bias $\left(B_{\mathrm{D}}^{\prime \prime}\right)$ (Donaldson, 1992). Discrimination refers to participants' ability to discriminate between the control items and the misled items, and bias refers to the likelihood that they would report seeing the test items in the slides versus reading about them in the narrative.

If telling participants that they received a cognitionenhancing drug increases their source monitoring, we would expect told drug participants to be better able than told placebo participants to discriminate between the items that they saw in the slides versus those that they read about in the narrative. Moreover, we would not expect a bias to accompany this increase in discrimination because a bias would suggest that participants had a tendency to report, for example, that they saw all the items in the slides, rather than actually distinguishing between the two sources of the items.

We compared the abilities of told drug and told placebo participants to discriminate between the control and the misled items and found a main effect for instruction; that is, told drug participants' discrimination $(M=.78$, $S D=.22)$ was better than told placebo participants' discrimination $(M=.63, S D=.30)[F(1,50)=4.86, p=$
$.03, f=.31]$. Additionally, paired $t$ tests revealed that both told drug and told placebo participants' discrimination was better than chance $(.5)[t(25)=6.48, p<.01$ and $t(25)=2.08, p=.02]$. Overall, participants were better than chance at distinguishing between items they saw and items they read about, but telling them that they had taken a cognition-enhancing drug further improved this discrimination.

We also compared told drug and told placebo participants' bias. A negative bias indicates that participants thought they saw all of the items (including the misled items) in the slides; in other words, a negative bias is consistent with the misinformation effect. A positive bias indicates that participants thought they read about all of the items (including the control items) in the narrative. A value of zero indicates no bias. $t$ tests revealed that told placebo participants had a significant negative bias $[M=$ $-.30, S D=.63, t(25)=2.38, p=.02]$, whereas told drug participants had no significant bias $[M=.18, S D=$ $.75, t(25)=1.25, p=.22]$. A one-way ANOVA revealed that this difference in bias between the two drug instructions was a significant main effect $[F(1,50)=6.27, p<$ $.05, f=.35]$. These results suggest that, consistent with the misinformation effect, told placebo participants were biased toward reporting that they saw the control and misled items in the slides, whereas told drug participants did not show this bias.

Overall, our results are consistent with the two ways we hypothesized that a placebo might affect source monitoring. First, told drug participants were better at discriminating between the information that they saw and the information that they read than told placebo subjects were, which suggests that told drug participants engaged in more deliberate source monitoring. Told drug participants also gave higher ratings to their cognitive abilities than did told placebo participants, which suggests that they were able to perform effortful source monitoring more easily. Second, told drug participants were slightly more confident about their answers than told placebo participants were, which indicates a tendency on the part of the told drug participants to trust their own memories of the slides rather than rely on the narrative recounting of the events in the slides.

Interestingly, we found that told placebo participants were biased toward reporting that they had seen items that they had actually only read about. This finding is consistent with the misinformation effect: Told placebo participants may have been biased toward reporting that they saw the items because they could not remember the original items and had to rely on the PEI (see Loftus, 2005). Relatedly, Hekkanen and McEvoy (2002) found that participants with more stringent source monitoring criteria were less susceptible to misleading information than were those with more lax criteria. Hekkanen and McEvoy suggested that participants with lax criteria were more likely to report that they had seen the misleading items, because these were the items they had encoded most recently.

Our results also fit with recent research exploring the mechanisms behind imagination inflation - the increase in confidence that a fictitious childhood event really 
happened, after one has spent time imagining that event (Garry, Manning, Loftus, \& Sherman, 1996). Sharman, Garry, and Hunt (2005) found that giving participants two cues about the source of the imagined events boosted their source monitoring abilities and helped them resist imagination inflation. This body of research, including our results, suggests that when people are given information-such as source cues or cognition-enhancing placebos - that alerts them to the source of their memories, they are able to avoid memory distortions.

Our results also resonate with work on mindfulness, which is a state of awareness in which people are sensitive to context (Langer, 1989) - that is, have a specific mindset for a given situation that drives their behavior (Langer, 2004 , personal communication). For example, participants who dressed as pilots and sat in a working flight simulator were better at reading the markings on a plane in front of them than were those who sat in a nonworking simulator (Langer, Dillon, Kurtz, \& Katz, 1998). Participants in the working simulator may have developed a "pilot mindset" that caused them to adjust their behavior to be more like that of pilots - in this case, by having a sharper sense of vision. By contrast, participants in the nonworking simulator may have been more aware that they were pretending to fly and consequently did not adjust their behavior. Similarly, participants in Dijksterhuis and van Knippenberg's 1998 study imagined either a professor's behaviors or a secretary's. When later answering trivia questions, participants who imagined professor behaviors outperformed those who imagined secretary behaviors. This research suggests that when people adopt specific mindsets, their performance in a relative context is better than that of people who do not adopt these mindsets.

In much the same way that the working simulator may have invoked a "pilot mindset" or imagining a professor may have invoked a "smart mindset," our drug instruction may have invoked a "cognitive improvement mindset," which resulted in better eyewitness memory performance. Indeed, Langer (1989) suggests that when people take a substance that they believe will have a particular effect, they essentially fool themselves into changing from one mental state to another. Thus, our told drug participants may have adopted a mental state in which they behaved in the way that they thought R273 caused people to behave: better able to focus and detect changes in their visual fields. Thus, the told drug participants modified their sourcemonitoring behavior and detected more discrepancies in the narrative. In contrast, the told placebo participants did not have the same mindset, nor did they adjust their source monitoring behaviors. This explanation raises the possibility that mindfulness may lead to increased sourcemonitoring behavior or that increased source-monitoring behavior leads to an increase in mindfulness. Either way, we cannot rule out the possibility that the relationship may be reciprocal and interactive. ${ }^{3}$ However, a study that asked participants to imagine the traits of a radar operator versus the traits of someone whose profession is contemplative, such as a poet or a monk, might lead to a pattern similar to the one we found here.

There are theoretical and practical implications for our findings. Theoretically, our results suggest that changing people's mindsets - even without the power of placebos - may help to reduce eyewitness inaccuracy. It might be fruitful to manipulate both mindfulness and placebo effects to determine the extent to which they share overlapping mechanisms. Practically, our results have implications for the myriad consumers who buy "smart drinks" that claim to increase concentration and decrease forgetfulness. Do they work? Our results suggest that as long as people adopt the right frame of mind, the answer is yes.

\section{AUTHOR NOTE}

Correspondence concerning this article should be sent to S. L. Clifasefi, Addictive Behaviors Research Center, University of Washington, Box 351629, Seattle, WA 98195 (e-mail: seemac@u.washington.edu).

\section{REFERENCES}

Assefi, S. L., \& GARry, M. (2003). Absolut ${ }^{\circledR}$ memory distortions: Alcohol placebos influence the misinformation effect. Psychological Science, 14, 77-80.

CoHen, J. (1988). Statistical power analysis for the behavioral sciences (2nd ed.). Hillsdale, NJ: Erlbaum.

Dijksterhuis, A., \& VAn Knippenberg, A. (1998). The relation between perception and behavior, or how to win a game of Trivial Pursuit. Journal of Personality \& Social Psychology, 74, 865-877.

Donaldson, W. (1992). Measuring recognition memory. Journal of Experimental Psychology: General, 121, 275-277.

Eprs, J., Monk, C., Savage, S., \& Marlatt, G. A. (1998). Improving credibility of instructions in the balanced placebo design: A misattribution manipulation. Addictive Behaviors, 23, 427-435.

Garry, M., Manning, C. G., Loftus, E. F., \& Sherman, S. J. (1996). Imagination inflation: Imagining a childhood event inflates confidence that it occurred. Psychonomic Bulletin \& Review, 3, 208-214.

HekKanen, S. T., \& McEvoy, C. (2002). False memories and sourcemonitoring problems: Criterion differences. Applied Cognitive Psychology, 16, 73-85.

Johnson, M. K., Hashtroudi, S., \& Lindsay, D. S. (1993). Source monitoring. Psychological Bulletin, 114, 3-28.

KIRSCH, I., \& LynN, S. J. (1999). Automaticity in clinical psychology. American Psychologist, 54, 504-515.

Kvavilashvili, L., \& Ellis, J. A. (1999). The effects of positive and negative placebos on human memory performances. Memory, 7, 421-437.

LAnger, E. J. (1989). Mindfulness. Reading, MA: Addison-Wesley.

Langer, E. J., Dillon, M., Kurtz, R., \& Katz, M. (1998). Believing is seeing. Unpublished manuscript, Harvard University.

LindSAY, D. S. (1993). Eyewitness suggestibility. Current Directions in Psychological Science, 2, 86-89.

LofTus, E. F. (2005). Planting misinformation in the human mind: A 30-year investigation of the malleability of memory. Learning \& Memory, 12, 361-366.

Loftus, E. F., Loftus, G. R., \& Messo, J. (1987). Some facts about "weapon focus." Law \& Human Behavior, 11, 55-62.

Sharman, S. J., Garry, M., \& Hunt, M. (2005). Using source cues and familiarity cues to resist imagination inflation. Acta Psychologica, 120, 227-242.

Tousignant, J. P., Hall, D., \& Loftus, E. F. (1986). Discrepancy detection and vulnerability to misleading postevent information. Memory \& Cognition, 14, 329-338.

Vornik, L. A., Sharman, S. J., \& Garry, M. (2003). The power of the spoken word: Sociolinguistic cues influence the misinformation effect. Memory, 11, 101-109. 


\section{NOTES}

1. Note that for control items, participants were not forced to choose between the item they had seen in the slides and the item that had been used to mislead them in the narrative. They did not receive misleading information for these items. Instead, subjects chose between the item they had seen in the slides and the item used to mislead the subjects who - due to counterbalancing - had received misleading information about that item.

2. Results from 4 participants ( 2 told drug and 2 told placebo) were excluded from all analyses due to incomplete data.

3 . We thank an anonymous reviewer for this suggestion.

\section{APPENDIX}

Examples of Control and Misleading Items for Two Counterbalancing Conditions (Cells in Gray Indicate Misleading Items)

\begin{tabular}{|c|c|c|c|}
\hline $\begin{array}{l}\text { Item Seen in Slides } \\
\text { (Version 1) }\end{array}$ & $\begin{array}{l}\text { Item Read About in Narrative } \\
\text { (Narrative 1) }\end{array}$ & $\begin{array}{l}\text { Item Read About in Narrative } \\
\text { (Narrative 2) }\end{array}$ & Items in Test \\
\hline Yellow candle & Candle & White candle & $\begin{array}{l}\text { Yellow candle vs. white } \\
\text { candle }\end{array}$ \\
\hline Green notebook & Yellow notebook & Notebook & $\begin{array}{l}\text { Green notebook vs. } \\
\text { yellow notebook }\end{array}$ \\
\hline Red stapler & Stapler & Blue stapler & $\begin{array}{l}\text { Red stapler vs. blue } \\
\text { stapler }\end{array}$ \\
\hline Chemistry book & Computer book & Book & $\begin{array}{l}\text { Chemistry book vs. } \\
\text { computer book }\end{array}$ \\
\hline Mickey Mouse sweatshirt & Sweatshirt & Minnie Mouse sweatshirt & $\begin{array}{l}\text { Mickey Mouse sweatshirt vs. } \\
\text { Minnie Mouse sweatshirt }\end{array}$ \\
\hline$G Q$ magazine & Vogue magazine & Magazine & $\begin{array}{l}G Q \text { magazine vs. Vogue } \\
\text { magazine }\end{array}$ \\
\hline Open elevator door & Elevator door & Closed elevator door & $\begin{array}{l}\text { Open elevator door vs. } \\
\text { closed elevator door }\end{array}$ \\
\hline Blue towel & White towel & Towel & $\begin{array}{l}\text { White towel vs. blue } \\
\text { towel }\end{array}$ \\
\hline
\end{tabular}

